\title{
Raman Spectroscopy, X-Ray, SEM, and DTA Analysis of Alkali-Phosphate Glasses Containing $\mathrm{WO}_{3}$ and $\mathrm{Nb}_{2} \mathrm{O}_{5}$
}

\author{
L. Bih, ${ }^{1}$ M. Azrour, ${ }^{1}$ B. Manoun, ${ }^{2}$ M. P. F. Graça, ${ }^{3}$ and M. A. Valente ${ }^{3}$ \\ ${ }^{1}$ Equipe Sciences de Matériaux, FST-Errachidia, Errachidia, Morocco \\ ${ }^{2}$ Equipe Matériaux et Environnement, Laboratoire de Chimie Appliquée et Environnement, Université Hassan 1er, Settat, Morocco \\ ${ }^{3}$ Physics Department (I3N), Aveiro University, Campus Universitário de Santiago, Aveiro, Portugal
}

Correspondence should be addressed to L. Bih; bihlahcen@yahoo.fr

Received 11 June 2012; Revised 9 August 2012; Accepted 29 August 2012

Academic Editor: Christoph Krafft

Copyright $\odot 2013 \mathrm{~L}$. Bih et al. This is an open access article distributed under the Creative Commons Attribution License, which permits unrestricted use, distribution, and reproduction in any medium, provided the original work is properly cited.

\begin{abstract}
New phosphate glasses in the quaternary system (50-x) $\mathrm{A}_{2} \mathrm{O}-x \mathrm{WO}_{3}-10 \mathrm{Nb}_{2} \mathrm{O}_{5}-40 \mathrm{P}_{2} \mathrm{O}_{5}$, with $x=0$; 30 and $\mathrm{A}=\mathrm{Li}$ or Na were prepared by the melt quenching method. The effect on the crystallization behaviour of the glass due to the introduction of $\mathrm{WO}_{3}$ into the glass composition and, consequently, the diminishing of the molar amount of the alkaline oxide and the decreasing of the molar ratio between network modifiers and network formers $(\mathrm{M} / \mathrm{F})$ was studied. The prepared glasses were heat-treated in air, at $550^{\circ} \mathrm{C}, 600^{\circ} \mathrm{C}$, and $650^{\circ} \mathrm{C}$ for 4 hours. The structure, of the obtained samples, was studied by differential thermal analysis (DTA), $\mathrm{X}$-ray powder diffraction (XRD), and Raman spectroscopy and the morphology by scanning electron microscopy (SEM). It was found that the replacement of $\mathrm{Li}_{2} \mathrm{O}$ or $\mathrm{Na}_{2} \mathrm{O}$ by $\mathrm{WO}_{3}$ reduces the number of the crystallised phases. In the lithium-niobiophosphate glasses, the presence of $\mathrm{WO}_{3}$ promotes the formation of $\mathrm{NbOPO}_{4}$ instead of the $\mathrm{LiNbO}_{3}$ phase and reduces the formation of orthoand pyro-phosphate phases. The thermal treatments affect the arrangements of the network structure of the AW40-glasses.
\end{abstract}

\section{Introduction}

Glass-ceramic composite materials have been a subject of intensive interest during the last decades. The goal for the development of such materials has been to achieve a combination of properties not achievable by any of the elemental materials alone.

Phosphate glasses have received considerable attention in the past few years due to the synthesis of new glass compositions with high chemical stability. The improvement of chemical stability [1-3] stimulated the application of phosphate glasses in several fields of materials science, such as fast ionic conductors [4], semiconductors [5], photonic materials [6-9], hermetic seals [10], rare-earth ion host solid state lasers [11], and biomedical materials [12]. The structure of these glasses consists of $\mathrm{PO}_{4}$ tetrahedra, which can be attached to a maximum of three neighbouring tetrahedra forming a three-dimensional network as in vitreous $\mathrm{P}_{2} \mathrm{O}_{5}$. The addition of metal oxides to the glass leads to a depolymerisation of the network, with the breaking of $\mathrm{P}-\mathrm{O}-\mathrm{P}$ linkages and the creation of nonbridging oxygen. The modifying cations can provide ionic cross-linking between the nonbridging oxygen of two phosphate chains, thus increasing the bond strength of this ionic cross-link and improving the mechanical strength and chemical durability of the glasses [1]. Niobium phosphate glasses have been investigated because they might be used in a wide range of applications, such as waste form for radioactive waste immobilization [13], rare-earth ion hosts for laser glasses [14], glass fibers and optical lenses [15, 16], hermetic sealing [17], electrodes [18], and agricultural applications [19]. Besides that, phosphate glasses are easy to produce at relatively low temperatures $\left(900-1200^{\circ} \mathrm{C}\right)$.

Niobiophosphate glass compositions such as $\mathrm{P}_{2} \mathrm{O}_{5}$ $\mathrm{Nb}_{2} \mathrm{O}_{5}-\mathrm{V}_{2} \mathrm{O}_{5}-\mathrm{TiO}_{2}$ and $\mathrm{P}_{2} \mathrm{O}_{5}-\mathrm{Nb}_{2} \mathrm{O}_{5}-\mathrm{V}_{2} \mathrm{O}_{5}-\mathrm{Fe}_{2} \mathrm{O}_{3}$, investigated by vibrational spectroscopy, exhibit structural features, characterized by $\mathrm{NbO}_{4}$ and $\mathrm{NbO}_{6}$ units [20]. Since several niobiophosphate glasses are $\mathrm{Nb}$-rich and Li-rich, their application as precursors to glass composites containing embedded $\mathrm{LiNbO}_{3}$ ferroelectric crystals has been proposed [21]. Recently, Graça et al. [22] prepared $\mathrm{LiNbO}_{3}$ glassceramic materials from the $\mathrm{Li}_{2} \mathrm{O}-\mathrm{Nb}_{2} \mathrm{O}_{5}-\mathrm{SiO}_{2}$ glasses by controlled crystallization. The dielectric properties of these 
glass-ceramics materials show better properties than their parent glasses [22]. More recently, Graça et al. [23] showed the effect of the network former on the nature of the crystallized phases in the glass-ceramics matrix, by analysing the crystallization of the $\mathrm{Li}_{2} \mathrm{O}-\mathrm{Nb}_{2} \mathrm{O}_{5}-\mathrm{P}_{2} \mathrm{O}_{5}$ glasses inducing the formation of multiple phases in opposite trends than that seen in silicate-based glasses.

In the present work, niobium phosphate glasses containing tungsten oxide belonging to the (50- $x) \mathrm{A}_{2} \mathrm{O}-(x) \mathrm{WO}_{3}$ $10 \mathrm{Nb}_{2} \mathrm{O}_{5}-40 \mathrm{P}_{2} \mathrm{O}_{5}(x=0$ and $30 ; \mathrm{A}=\mathrm{Li}, \mathrm{Na})$ systems were prepared by the melt quenching technique. These glasses contain three types of components. $\mathrm{P}_{2} \mathrm{O}_{5}$ is a well-known network former with $\mathrm{PO}_{4}$ structural units with one of the four oxygen atoms in the $\mathrm{PO}_{4}$ tetrahedron being doubly bonded to the phosphorus atom with the substantial $\pi$-bond character to account for the pentavalency of phosphorus. $\mathrm{Nb}_{2} \mathrm{O}_{5}$ and $\mathrm{WO}_{3}$ are incipient glass network formers and as such do not readily form glass but do so in the presence of modifiers like $\mathrm{A}_{2} \mathrm{O}(\mathrm{A}=\mathrm{Li}, \mathrm{Na})$ with $\mathrm{MO}_{4}$ and $\mathrm{MO}_{6}$ $(\mathrm{M}=\mathrm{Nb}, \mathrm{W})$ structural units. Generally, niobium and tungsten are located in octahedral sites in phosphate glasses. The tungsten oxide structural groups are expected to mix easily in a $\mathrm{A}_{2} \mathrm{O}-\mathrm{Nb}_{2} \mathrm{O}_{5}-\mathrm{P}_{2} \mathrm{O}_{5}$ network because some of the Raman vibrational bands of the structural groups of these ions lie in the same region as those of $\mathrm{NbO}_{6}$ and $\mathrm{P}-\mathrm{O}-\mathrm{P}$ structural units and are expected to occupy a variety of sites with different crystal field strengths due to site variability. According to these structural considerations, it is expected that the interaction between phosphate and niobate/tungsten anions in niobium-tungsten-containing phosphate glasses would be simpler because the coordination number of phosphorous atoms for oxygen is usually constant at four in phosphate glasses. In this study, the as-prepared glasses were heat-treated at different temperatures in order to promote crystallization and they were investigated using differential thermal analysis, X-ray diffraction, and Raman spectroscopy to provide a structural characterization and SEM microscopy to analyse their morphology.

\section{Experimental Details}

2.1. Sample Preparation. The glasses with composition (50x) $\mathrm{A}_{2} \mathrm{O}-x \mathrm{WO}_{3}-10 \mathrm{Nb}_{2} \mathrm{O}_{5}-40 \mathrm{P}_{2} \mathrm{O}_{5}(x=0$ and $30 ; \mathrm{A}=\mathrm{Li}$, $\mathrm{Na}$ ) (\% mole) were prepared by the melt quenching method using AR-grade chemicals $\mathrm{Li}_{2} \mathrm{CO}_{3}, \mathrm{Na}_{2} \mathrm{CO}_{3}, \mathrm{Nb}_{2} \mathrm{O}_{5}, \mathrm{WO}_{3}$, and $\mathrm{NH}_{4} \mathrm{H}_{2} \mathrm{PO}_{4}$. Approximately $10 \mathrm{~g}$ of chemicals were thoroughly mixed and melted in a platinum crucible at $1400 \mathrm{~K}$ in an electric muffle furnace for about one hour. The melt was swirled occasionally to ensure homogeneity. The coinshaped glass samples were obtained by pouring the melts onto a stainless steel plate and pressed with another plate.

In this work, the samples without $\mathrm{W}$ will be called Li-40 or Na-40 and the samples with $\mathrm{W}$ will be called LiW-40 and NaW-40.

The obtained samples were heat-treated in air at 500, 600, and $650^{\circ} \mathrm{C}$ in agreement with the results of the differential thermal analysis.
2.2. X-Ray Diffraction. The obtained products was examined by X-ray diffraction analysis using a Seifert XRD $3000(\mathrm{Cu}$ $\mathrm{K} \alpha$ radiation, $\lambda=1.5406 \AA$ ). The diffraction patterns were recorded at room temperature in the range $5-70^{\circ}(6 \mathrm{~h})$ in steps of $0.02^{\circ}$.

\subsection{Density, Molar Volume, and Differential Scanning Calori-} metric Measurements. The density $(D)$ of all the samples was calculated by Archimedes's method with Xylene as buoyant liquid. The molar volume $\left(V_{M}\right)$ of the samples was calculated using the relation $V_{M}=M_{T} / D$ where $M_{T}$ is the total molecular weight.

The glass transition temperature $\left(T_{g}\right)$ of all the samples was determined using differential thermal analysis (Linseis apparatus) at the rate of $5 \mathrm{~K} / \mathrm{min}$.

2.4. Raman Spectroscopy Analysis. The Raman spectra were recorded with a HoloSpec (f/1.8i, Kaiser Optical Systems) equipped with a holographic transmission grating and thermoelectrically cooled two-dimensional multichannel CCD detector (Newton, Andor Technology, $1600 \times 400$ pixels, $\left.-60^{\circ} \mathrm{C}\right)$. An argon laser, with the wavelength centred at $514.5 \mathrm{~nm}$, was used for the excitation. The spectrometer was calibrated by fluorescence lines of the neon lamp. Nonpolarized Raman spectra were collected in the back-scattering geometry, in the range $180-2280 \mathrm{~cm}^{-1}$, with a resolution of $3 \mathrm{~cm}^{-1}$. Accuracy of spectral measurements, resulting from the wavelength calibration procedure and experimental conditions, is estimated to be about $1.5 \mathrm{~cm}^{-1}$. Precision of the reported peak positions, as represented by standard errors obtained in peak fits is $0.04 \mathrm{~cm}^{-1}$. The acquisition time was between 2 and $5 \mathrm{~s}$. All the measurements were made at room temperature.

2.5. Scanning Electron Microscopy. The microstructure and morphology of the glass and glass-ceramics were observed by scanning electron microscopy (SEM), performed in a Hitachi S4100-1 system, on the free surface and on the fracture surface of all samples covered with carbon before microscopic observation.

\section{Results and Discussion}

3.1. Density and Molar Volume Parameters. The density (D) values of the lithium (LiW-40) and sodium (NaW-40) glasses are 3.21 and $3.19 \mathrm{~g} / \mathrm{cm}^{3}$, respectively. The values of molar volume, calculated using the formula $V_{M}=M_{T} / D$, where $M_{T}$ is the total molecular weight, are $43.21 \mathrm{~cm}^{3}$ and $46.50 \mathrm{~cm}^{3}$ for the LiW-40 and NaW-40 glasses, respectively. These values, density and molar volume, of both tungsten-based glasses are higher than the values obtained for the Li-40 glass $(D=$ $2.69 \mathrm{~g} / \mathrm{cm}^{3}$ and $V_{M}=36.55 \mathrm{~cm}^{3}$ ) [23]. The observed increase in the density when the alkaline oxide is substituted by $\mathrm{WO}_{3}$ oxide can be explained due to the replacement of an alkali cation ( $\mathrm{Li}$ or $\mathrm{Na}$ ) by a heavier ion (W), and possibly, denser amorphous structures are achieved due to stronger crosslinking between phosphate networks. However, the number of oxygen anions rises gradually in the glass network with the 
increase of $\mathrm{WO}_{3}$ content and thus the addition of $\mathrm{WO}_{3}$ can promote a relatively open structure causing an increase in the molar volume. This behaviour was observed in the present case, where the molar volume of the glass systems increases with the growth of the $\mathrm{WO}_{3}$ concentration, suggesting that the molecular volume is influenced by the number of $\mathrm{O}^{2-}$ ions per unit of volume. Apparently, while substituting $\mathrm{A}_{2} \mathrm{O}$ by $\mathrm{WO}_{3}$, the molar volume should decrease because two cations per unit found for $\mathrm{A}_{2} \mathrm{O}$ are replaced by a single cation in $\mathrm{WO}_{3}$. The increase of molar volume in tungsten-glasses suggests that the excess of oxygen, due to the substitution of $\mathrm{Li}_{2} \mathrm{O}$ or $\mathrm{Na}_{2} \mathrm{O}$ by $\mathrm{WO}_{3}$, induces the formation of additional nonbridging oxygen and/or the formation of voluminous niobium and/or tungsten structural units such as $\mathrm{WO}_{6} / \mathrm{NbO}_{6}$ octahedron in the glass network.

3.2. Glass Transition Temperature. The DTA spectra of the glasses LiW-40 and NaW-40 are shown in Figure 1. Typical glass parameters: $T_{g}$ (glass transition temperature), $T_{x}$ (the onset of crystallization temperature), and $T_{c}$ (crystallization temperature) were extracted from these curves and are summarized in Table 1. The characteristic temperatures are indicated by arrows in Figure 1. Both glasses show two crystallisation temperatures $\left(T_{c 1}\right.$ and $\left.T_{c 2}\right)$, indicating that, at least, two crystalline phases are formed in their network by heating. The influence of the $\mathrm{WO}_{3}$ content on the thermal properties of the glass is seen by comparing the DTA spectrum of Li-40 glasses $\left(40 \mathrm{P}_{2} \mathrm{O}_{5}-50 \mathrm{Li}_{2} \mathrm{O}-10 \mathrm{Nb}_{2} \mathrm{O}_{5}(\% \mathrm{~mol})\right)$ [23] and the spectra of LiW-40 and NaW-40 (Figure 1). It must be noticed that in these compositions the $\mathrm{P}_{2} \mathrm{O}_{5}$ and $\mathrm{Nb}_{2} \mathrm{O}_{5}$ molar concentration were kept equal. One can note that the $T_{g}$ value for the glass $\mathrm{LiW}-40\left(T_{g}=340^{\circ} \mathrm{C}\right)$ is lower than that of $\mathrm{Li}-40\left(T_{g}=450^{\circ} \mathrm{C}\right)$ [23]. It was expected that with the substituting of $\mathrm{Li}_{2} \mathrm{O}$ by $\mathrm{WO}_{3}$, the glass transition temperature should increase because of the increase of the number of strong $\mathrm{W}-\mathrm{O}-\mathrm{P}$ and $\mathrm{W}-\mathrm{O}-\mathrm{W}$ linkages. Thus, the observed decrease of the glass transition temperature from Li-40 to LiW-40 samples (Figure 1, Table 1) indicates that the replacement of $\mathrm{Li}_{2} \mathrm{O}$ by $\mathrm{WO}_{3}$ induces the depolymerisation of the network and the creation of nonbridging oxygen ions. In fact, this substitution is associated with the increase of $\mathrm{O} / \mathrm{P}$ ratio. The depolymerisation of the network is in agreement with the fact that the molar volumes of LiW-40 and NaW-40 are higher than the corresponding free- $\mathrm{WO}_{3}$ glass (Table 1).

For the evaluation of the thermal stability of glasses, the $\Delta T=T_{x 1}-T_{g}$ criterion was applied. Higher values of this criterion usually correspond to a higher thermal stability and glass-forming ability. The obtained values of the $\Delta T$ for the studied glasses are given in Table 1. It can be verified that the value of $\Delta T=123$, measured for LiW-40 glass, is higher than the $\Delta T=70$ obtained for the NaW-40 glass. It means that NaW-40 glass has a lower thermal stability and a higher crystallization tendency. However, these AW40 glasses are thermally more stable than the $\mathrm{WO}_{3}$-free glass, which has a smaller value of $\Delta T=30$ [23]. The DTA of the tungsten-free glass, Li-40 [23], exhibits a broad exothermic peak at $480-600^{\circ} \mathrm{C}$ [23]. This broadband can be ascribed to the simultaneous crystallization of more than one phase

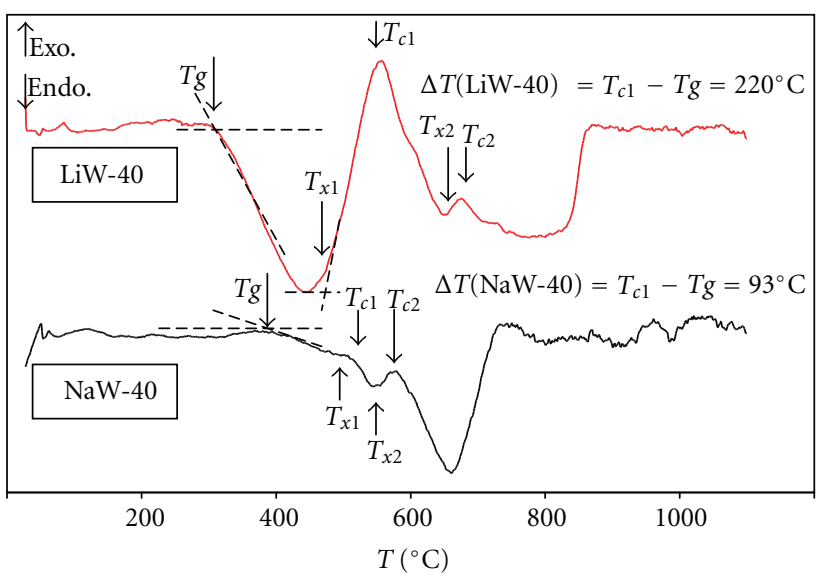

Figure 1: DTA curves of the AW-40 $(\mathrm{A}=\mathrm{Li}, \mathrm{Na})$ glasses.

from the glass matrix. For instance, based upon the Raman spectra and the $\mathrm{X}$-ray diffraction, this broad exothermic peak can be attributed to the crystallization of $\mathrm{LiNbO}_{3}, \mathrm{Li}_{3} \mathrm{PO}_{4}$, $\mathrm{Li}_{4} \mathrm{P}_{2} \mathrm{O}_{7}$, and $\mathrm{LiPO}_{3}$ crystalline phases. Since the shape of the crystallisation peak in the DTA pattern of both LiW-40 and NaW-40 glasses is different to that of $\mathrm{WO}_{3}$-free glass, one can anticipate that the nature of the crystallised phases issued from these glasses could be different. Based on the fact that the alkali content in LiW-40 and NaW-40 glasses is lower than that of for a $\mathrm{WO}_{3}$-free glass, one can expect the formation of niobium- and/or tungsten-phosphate phases rather than alkali phosphate phases. This hypothesis is well confirmed by $\mathrm{X}$-ray diffraction and Raman analysis in the next sections.

3.3. X-Ray Diffraction and SEM Micrographs. The glassy state of the LiW-40 and NaW-40 samples before heat treatments is confirmed by X-ray diffraction. XRD patterns of the crystallized samples are shown in Figure 2. The crystalline phases for the samples after heat treatment were identified by comparing the X-ray diffraction pattern shown in Figure 2 with the JCPDS file $\mathrm{NbOPO}_{4}(27-1316)$ and $\mathrm{Li}_{4} \mathrm{P}_{2} \mathrm{O}_{7}$ (771045). It must be mentioned that all the diffraction peaks associated with the $\mathrm{NbOPO}_{4}$ phase were detected and only the major peak of the $\mathrm{Li}_{4} \mathrm{P}_{2} \mathrm{O}_{7}$ was observed. In the $\mathrm{Li}$ 40 glass $\left(\mathrm{WO}_{3}\right.$-free), it was also found crystallization peaks corresponding to $\mathrm{LiPO}_{3}, \mathrm{Li}_{3} \mathrm{PO}_{4}$, and $\mathrm{LiNbO}_{3}$ phases [23]. Thus, the replacement of $\mathrm{Li}_{2} \mathrm{O}$ by $\mathrm{WO}_{3}$ reduces the number of the crystallised phases and consequently, the absence of the alkali-phosphates phases (e.g., $\mathrm{Li}_{3} \mathrm{PO}_{4}$ and $\mathrm{LiPO}_{3}$ ) in the crystallised samples correlates well with the alkali content in the glasses.

When $\mathrm{WO}_{3}$ is added instead of $\mathrm{A}_{2} \mathrm{O}$ modifier oxide, it can be incorporated into the glass network as corner-sharing $\left[\mathrm{WO}_{6}\right]$ octahedral units. The formula $\left[\mathrm{WO}_{6}\right]$ suggests that no additional oxygen atoms are required for the coordination of tungsten since $\mathrm{WO}_{3}$ itself can almost generate $\left[\mathrm{WO}_{6 / 2}\right]$ in the network. However, the presence of niobium in the network as corner-sharing $\left[\mathrm{NbO}_{6 / 2}\right]$ octahedral units suggests that additional oxygen atoms are required for the coordination of niobium (since $\mathrm{Nb}_{2} \mathrm{O}_{5}$ itself can almost generate $\left[\mathrm{NbO}_{5 / 2}\right]$ 
TABLE 1: Physical parameters for AW-40 glasses.

\begin{tabular}{|c|c|c|c|c|c|}
\hline Glass & Density $\left(\mathrm{g} / \mathrm{cm}^{3}\right)$ & $V_{M}\left(\mathrm{~cm}^{3}\right)$ & $\operatorname{Tg}\left({ }^{\circ} \mathrm{C}\right)$ & $T_{x 1}\left({ }^{\circ} \mathrm{C}\right)$ & $\Delta T=T_{x 1}-T_{g}$ \\
\hline $\begin{array}{l}\mathrm{WO}_{3} \text {-free }[23] \\
40 \mathrm{P}_{2} \mathrm{O}_{5}-10 \mathrm{Nb}_{2} \mathrm{O}_{5}-50 \mathrm{Li}_{2} \mathrm{O}\end{array}$ & 2.69 & 36.55 & 450 & 480 & 30 \\
\hline $\begin{array}{l}\mathrm{LiW} 40 \\
40 \mathrm{P}_{2} \mathrm{O}_{5}-10 \mathrm{Nb}_{2} \mathrm{O}_{5}-20 \mathrm{WO}_{3}-30 \mathrm{Li}_{2} \mathrm{O}\end{array}$ & 3.21 & 43.21 & 340 & 472 & 123 \\
\hline $\begin{array}{l}\mathrm{NaW} 40 \\
40 \mathrm{P}_{2} \mathrm{O}_{5}-10 \mathrm{Nb}_{2} \mathrm{O}_{5}-20 \mathrm{WO}_{3}-30 \mathrm{Na}_{2} \mathrm{O}\end{array}$ & 3.19 & 46.50 & 420 & 490 & 70 \\
\hline
\end{tabular}

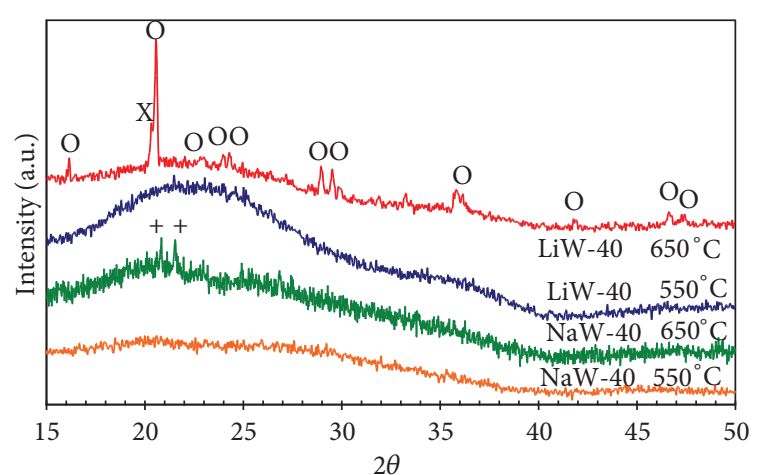

$$
\begin{aligned}
& \text { O } \mathrm{NbPO}_{5} \text { (ortho) } \\
& +\mathrm{NbPO}_{5} \text { (mono) } \\
& \mathrm{X} \mathrm{\textrm {Li } _ { 4 }} \mathrm{P}_{2} \mathrm{O}_{7}
\end{aligned}
$$

Figure 2: X-Ray diffraction patterns of the AW-40 glasses submitted to different heat treatments.

in the network), provided by the host network. One possible way for $\mathrm{Nb}^{5+}$ to get its six-oxygen coordination is to react with phosphate units according to the reaction: $\left[\mathrm{NbO}_{5 / 2}\right]+$ $\left[\mathrm{POO}_{3 / 2}\right] \rightarrow\left[\mathrm{NbO}_{6 / 2}\right]^{-}+\left[\mathrm{PO}_{4 / 2}\right]^{+}$. It is worth to note that the neutral phosphate unit $\left[\mathrm{POO}_{3 / 2}\right]$ can be formed only in the ultraphosphate region where the ratio $[\mathrm{O}] /[\mathrm{P}]<3$. Since in the $\mathrm{AW}-40$ glasses the $[\mathrm{O}] /[\mathrm{P}]=4.25$, one can state that the phosphate units with more than two nonbridging oxygen supply oxygen to niobium to form the oxygen-octahedrally coordinated $\mathrm{NbO}_{6}$ in the glasses. Thus, the formation of motifs of the niobium-phosphate $\mathrm{NbOPO}_{4}$ crystalline phase can be understood through the $[\mathrm{O}] /[\mathrm{P}]$ ratio. It must be noticed that $\mathrm{NbOPO}_{4}$ belongs to a subgroup of materials that exhibit anisotropic negative thermal expansion (NTE) at high temperature [24]. Under ambient conditions, $\mathrm{NbOPO}_{4}$ has been synthesized having a monoclinic structure $(a=$ $\left.13.097 \AA, b=5.280 \AA, c=13.228 \AA, \beta=120.334^{\circ}\right)$ [25] and also in a tetragonal structure $(a=6.389 \AA, c=4.105 \AA)$, which is $18 \%$ denser than the monoclinic phase [26]. Both phases of $\mathrm{NbOPO}_{4}$ are based on $\mathrm{NbO}_{6}$ octahedra and $\mathrm{PO}_{4}$ tetrahedra, which share corners to form three-dimensional networks. The twofold coordination of oxygen atoms in the structure facilitates transverse motion of oxygen in the $\mathrm{Nb}-\mathrm{O}-$ $\mathrm{P}$ linkages and results in negative thermal expansion [24]. It is well known that the structure of phosphate glasses is strongly dependent on the $\mathrm{O} / \mathrm{P}$ ratio of the glass composition and with the increase of the $\mathrm{O} / \mathrm{P}$ ratio, the phosphate network becomes more depolymerized and the ultraphosphate structure composed of cross-linked $\mathrm{Q}^{3}$ units $(\mathrm{O} / \mathrm{P}=2.5)$ changes to $(a)$ the chain-like metaphosphate structure made up of $\mathrm{Q}^{2}$ units $(\mathrm{O} / \mathrm{P}=3.0)$ to $(b)$ the pyrophosphate, $\mathrm{Q}^{1}$, structure $(\mathrm{O} / \mathrm{P}=$ 3.5) and finally to $(c)$ the orthophosphate structure consisting of isolated $\mathrm{Q}^{0}$ units $(\mathrm{O} / \mathrm{P}=4.0)$. In all of the $\mathrm{AW}-40$ glasses of the present work, the $\mathrm{O} / \mathrm{P}$ ratio is 4.25 , so the network structure is expected to be dominated by orthophosphate $\mathrm{Q}^{0}$ groups. For instance, the structure of $\mathrm{NbOPO}_{4}$ consists of $\mathrm{Q}^{0}$ units sharing corners with niobium $\mathrm{NbO}_{6}$ units. In agreement with the structural $\mathrm{O} / \mathrm{P}$ ratio, the $\mathrm{XRD}$ patterns of (Figure 2) show that in the LiW-40 sample, treated at $650^{\circ} \mathrm{C}$, the $\mathrm{NbOPO}_{4}$ phase crystallizes in the orthorhombic and in the NaW-40 sample in the monoclinic structure. The formation of different $\mathrm{NbOPO}_{4}$ structures can be related with the size of the alkali ion. Thus, increasing the size of the alkali, the phase symmetry decreases from orthorhombic to monoclinic, which can suggest that the presence of sodium ions in the glass matrix acts as an additional structural constraint which favours the formation of $\mathrm{NbOPO}_{4}$ with low symmetry.

Furthermore, the decrease of the content of the alkali ions from $40 \mathrm{P}_{2} \mathrm{O}_{5}-10 \mathrm{Nb}_{2} \mathrm{O}_{5}-50 \mathrm{~A}_{2} \mathrm{O}$ to $40 \mathrm{P}_{2} \mathrm{O}_{5}-10 \mathrm{Nb}_{2} \mathrm{O}_{5}$ $20 \mathrm{WO}_{3}-30 \mathrm{~A}_{2} \mathrm{O}(\mathrm{AW}-40)$ glass seems to favour the formation of $\mathrm{NbOPO}_{4}$ instead of the $\mathrm{LiNbO}_{3}$ phase. One possible explanation for this behaviour can be given bellow: since the roles of $\mathrm{Li}^{+}$and $\mathrm{Nb}^{5+}$ in the structure of phosphate-based glasses would be naturally different and all ions of $\mathrm{Li}^{+}$and $\mathrm{Nb}^{5+}$ in the original glasses would not be included into precipitated crystals, one can state that the major content of alkali ions are inside the glassy-matrix rather than in precipitated crystalline phases. Thus, the formation of $\mathrm{NbOPO}_{4}$ phase as shown in Figure 2 demonstrates that the major content of alkali $\mathrm{A}^{+}$ $(\mathrm{A}=\mathrm{Li}, \mathrm{Na})$ ions are probably stabilized in phosphate-based glasses and thus the presence of a small amount of alkali ion around niobium units is low enough to produce the formation of $\mathrm{ANbO}_{3}$ crystals, which could be identified by $\mathrm{X}$-ray diffraction, in crystallised samples. Moreover, Graça et al. [23] highlight that the crystallisation of the glass with high $\mathrm{Li}^{+} / \mathrm{Nb}^{5+}$ ratio (i.e., $\mathrm{WO}_{3}$-free glass) leads to the precipitation of $\mathrm{LiNbO}_{3}$ phase.

The SEM micrographs of the samples treated at $650^{\circ} \mathrm{C}$, presented in Figure 3, revealed the presence of particles with a spherical shape and linear size lower than $50 \mathrm{~nm}$ in both compositions. In all samples treated at temperatures below $650^{\circ} \mathrm{C}$, the presence of particles dispersed in the glass network was not observed. While the NaW-40 sample presents a higher number of particles, which should be related 


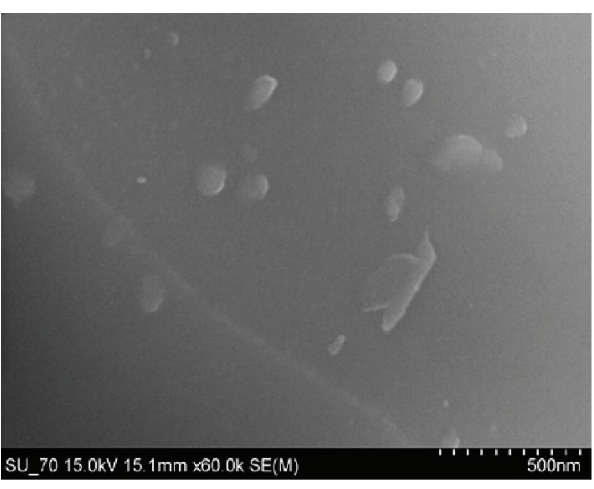

(a)

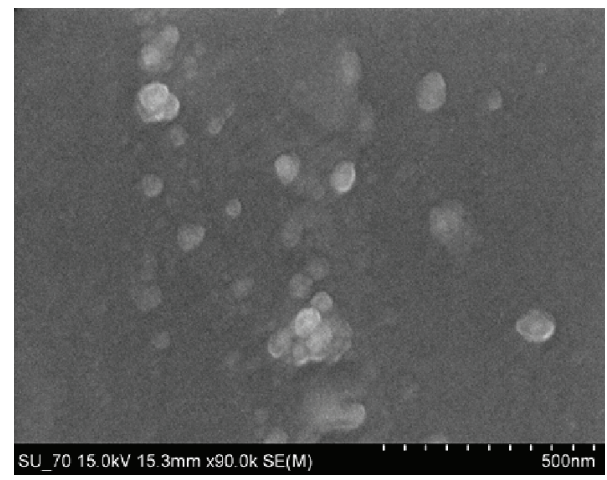

(b)

FIgURE 3: SEM micrographs of the LiW-40 (a) and NaW-40 (b) samples heat-treated at $650^{\circ} \mathrm{C}$ for 4 hours.

with $\mathrm{NbOPO}_{4}$ particles, the resolution of its XRD pattern (Figure 2) is very low compared to that of LiW-40. Thus, the resolution of the X-ray pattern depends on both the size and the content of the crystalline phases. Moreover, knowing that the spectra of the LiW-40 sample, treated at $650^{\circ} \mathrm{C}$, are a multiphase sample with well-defined diffraction peaks (Figure 2), it is suggested the existence of particles with a very small linear size, not detectable by SEM.

3.4. Raman Spectroscopy. Raman spectra of the AW-40 glasses and of the corresponding heat-treated glasses are shown in Figures 4(a) and 4(b). The spectra of AW40glasses, with and without heat treatment, are almost similar suggesting that the arrangement of the structural units in the glass matrix is not very much affected by the heat treatments of the glass. However, for the purposes of studying the effect of heat treatment, it is useful to deconvolute these spectra.

Previously reported structure [27-30] of phosphate glasses showed that the basic structural element of phosphate glasses is the $\left[\mathrm{PO}_{4}\right]$-tetrahedron. Their structures are usually presented using the $\mathrm{Q}^{n}$ terminology where $n$ represents the number of bridging oxygens (BO) per tetrahedron [28]. They start with the three-dimensional network of $\mathrm{Q}^{3}$ groups, an example of which is vitreous $\mathrm{P}_{2} \mathrm{O}_{5}\left(\mathrm{v}-\mathrm{P}_{2} \mathrm{O}_{5}\right)$. Changes in the structure caused by introducing other metallic oxides are most easily understood in the case of binary systems. The addition of modifying oxides leads to the scission of P-O$\mathrm{P}$ bonds and to the network depolymerization [29]. Acidic phosphate glasses which contain $\mathrm{P}_{2} \mathrm{O}_{5}$ greater than $50 \mathrm{~mol} \%$ have the structure of a three-dimensional network consisting of $\mathrm{Q}^{3}$ and $\mathrm{Q}^{2}$ groups. Metaphosphate glasses with $50 \mathrm{~mol} \%$ of modifying oxides consist of metaphosphate chains or rings formed by $\mathrm{Q}^{2}$ groups. These glasses do not tend to have separated phases and thus do not fulfil the criterion required for controlled glass-ceramic crystallization. The structure of polyphosphate glasses (inverse phosphate glasses), containing $<50 \mathrm{~mol} \% \mathrm{P}_{2} \mathrm{O}_{5}$, consists of chains formed by $\mathrm{Q}^{2}$ groups, $\mathrm{Q}^{1}$ and $\mathrm{Q}^{0}$ groups. The Raman spectrum of Li-40 shows broadbands at 925 and $265 \mathrm{~cm}^{-1}$, that can be attributed to the $\mathrm{P}-\mathrm{O}$ bending and to the vibration of $\mathrm{NbO}_{6}$ units, respectively [23]. Moreover, this glass does not promote the preparation of glass-ceramics with only $\mathrm{LiNbO}_{3}$ crystallites because in the Raman spectra of the heat-treated samples it is observed the $950 \mathrm{~cm}^{-1}\left(\mathrm{Li}_{3} \mathrm{PO}_{4}\right), 1050 \mathrm{~cm}^{-1}\left(\mathrm{Li}_{4} \mathrm{P}_{2} \mathrm{O}_{7}\right)$, and $1100 \mathrm{~cm}^{-1}$ $\left(\mathrm{LiPO}_{3}\right)$ vibration modes.

It is worth noting that the Raman bands of the asprepared Li-W40 and Na-W40 glasses are less broad than those observed in the spectrum of $\mathrm{WO}_{3}$-free glass [23]. Since the broadness of the bands is an indication of the amorphous character of a glass, it can be deduced that the amorphous order of the glasses LiW-40 and NaW-40 is lower than that of a $\mathrm{WO}_{3}$-free glass. Therefore, the decreasing of the amorphous character is associated with the substitution of weak ionic alkali-oxygen bonds by stronger covalent $\mathrm{W}-\mathrm{O}$ ones. This correlation is in agreement with the higher glass transition temperature of the Li-40 glass when compared to those of AW-40 $(\mathrm{A}=\mathrm{Li}, \mathrm{Na})$ glasses. Considering the chemical compositions of the glasses (Table 1), the calculated $[\mathrm{O}] /[\mathrm{P}]$ ratios are 3.75 and 4.25 for the $\mathrm{WO}_{3}$-free glass and for the AW-40 glasses, respectively and according to the $[\mathrm{O}] /[\mathrm{P}]$ criterion, the AW-40 glasses should exhibit a higher tendency toward faster structure arrangement-crystallization which is in agreement with the Raman results that shows larger bands for the $\mathrm{WO}_{3}$-free glass.

The Raman spectra of the LiW-40 and NaW-40 glasses (Figure 4) are different even if they present equal $[\mathrm{O}] /[\mathrm{P}]$ ratio. The width of the $800 \mathrm{~cm}^{-1}-1000 \mathrm{~cm}^{-1}$ high-frequency vibrations of NaW-40 glass $\left(\Delta=257 \mathrm{~cm}^{-1}\right)$ is larger than that of the homologous LiW-40 glass $\left(204 \mathrm{~cm}^{-1}\right)$ as expected from the presence of a lower distribution of structural units in the LiW-40. The XRD spectra of the NaW-40 sample treated at $650^{\circ} \mathrm{C}$ (Figure 2) presents diffraction peaks, assigned to the $\mathrm{NbOPO}_{4}$ (JCPDS 27-1316), whose low intensity is in agreement with the width of the Raman bands in the highfrequency region (Figure 4).

The changes of the Raman spectra with composition and treatment temperature are used to deduce the structural evolution of the samples. For these purposes, it is useful to divide the spectra into three regions: the high-frequency region, from 700 to $1300 \mathrm{~cm}^{-1}$, the middle-frequency, from 500 to $700 \mathrm{~cm}^{-1}$, and the low-frequency region, below $500 \mathrm{~cm}^{-1}$. The deconvolution of the Raman spectra of the AW-40 in 


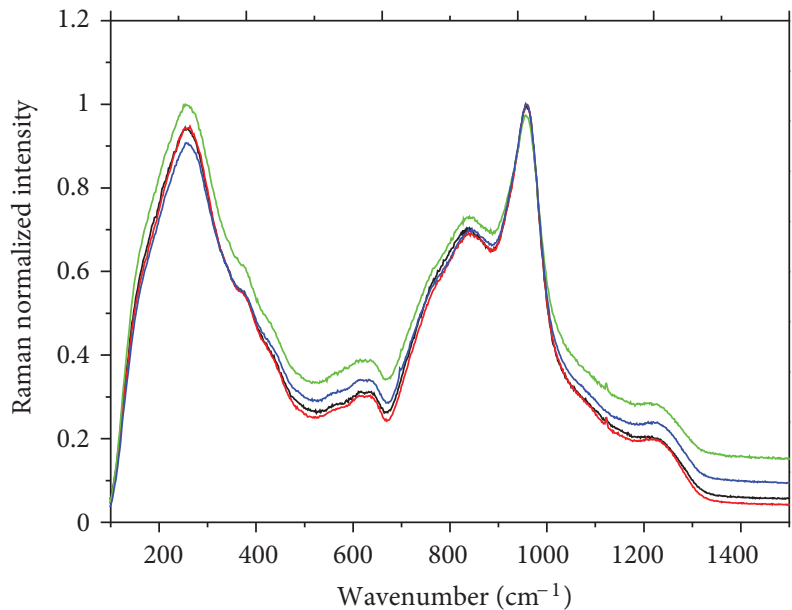

LiW-40

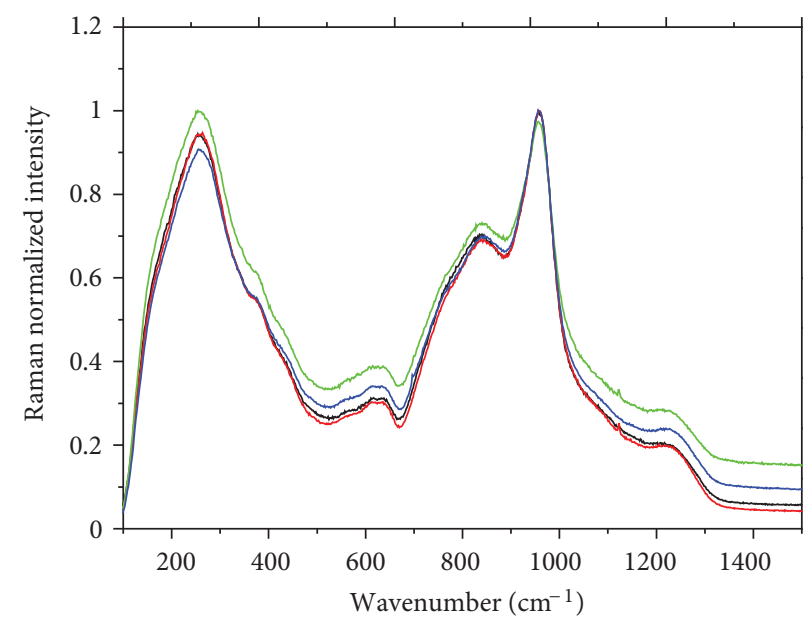

LiW-40

- Amb.

$-500^{\circ} \mathrm{C} / 4 \mathrm{~h}$ $-600^{\circ} \mathrm{C} / 4 \mathrm{~h}$

- $650^{\circ} \mathrm{C} / 12 \mathrm{~h}$

(a)

(b)

FIGURE 4: Raman spectra of AW-40 glasses in the frequency range $100-1500 \mathrm{~cm}^{-1}$ submitted to heat treatments at different temperatures: (a) Li; (b) Na.

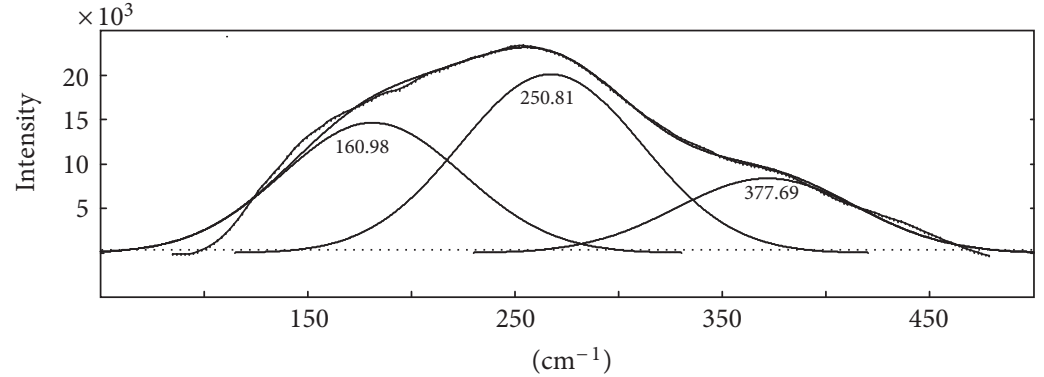

(a)

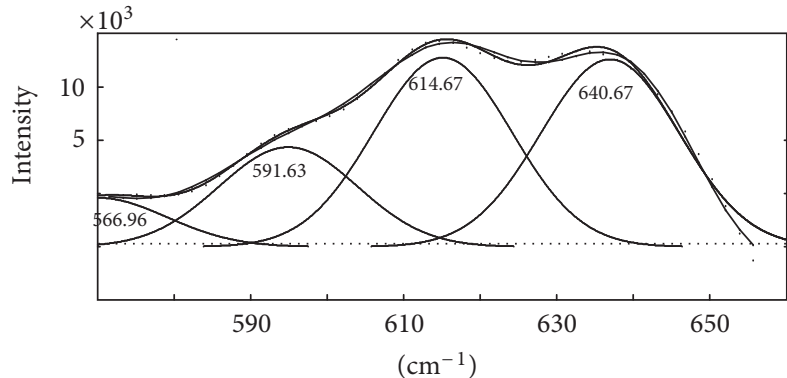

(b)

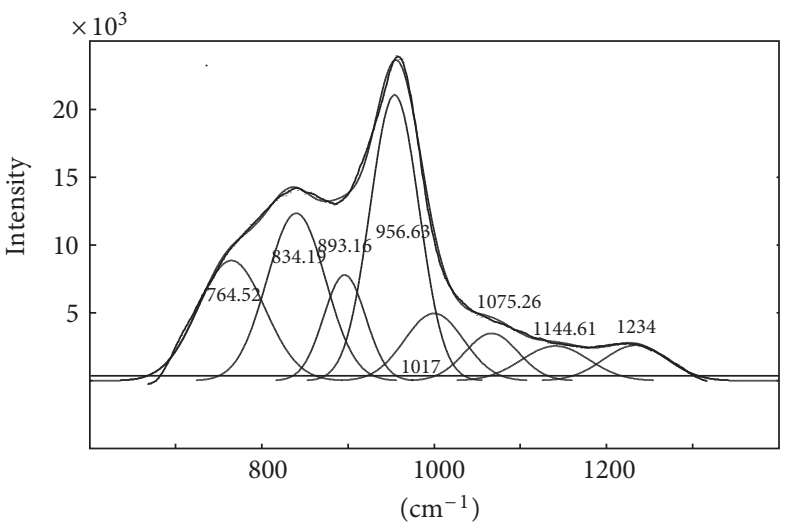

(c)

Figure 5: Deconvolution of the LiW-40 Raman spectrum in three frequency regions: (a) low, (b) medium, and (c) high. 


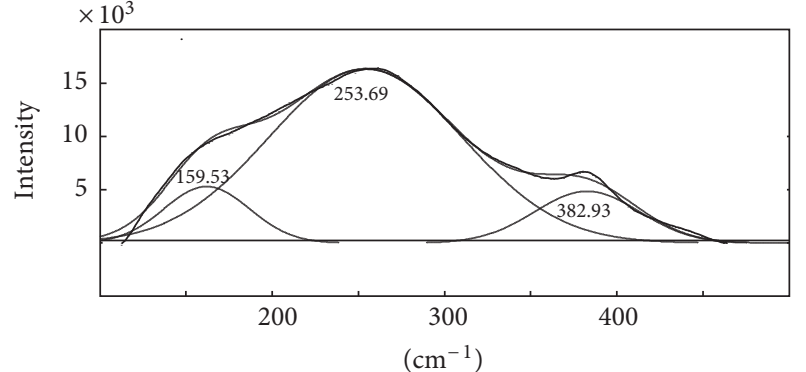

(a)

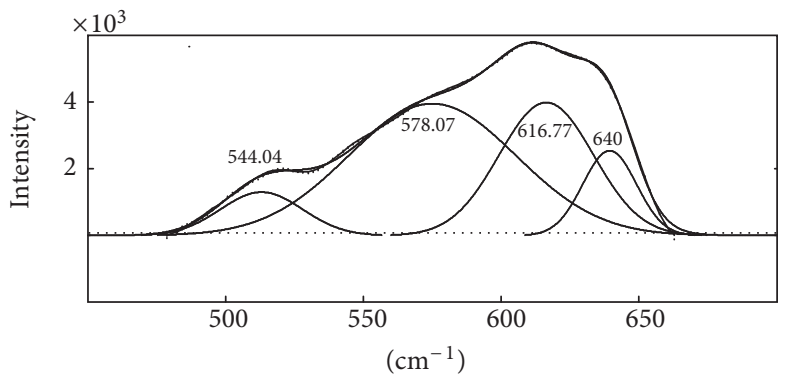

(b)

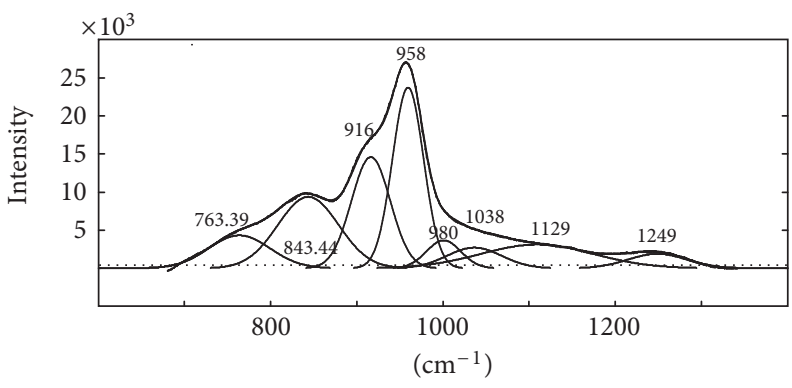

(c)

Figure 6: Deconvolution of the NaW-40 Raman spectrum in three frequency regions: (a) low, (b) medium, and (c) high.

these three frequency domains are shown in Figures 5 and 6 and their assignments are summarized in Table 2. The Raman spectrum of the LiW-40 presents a general behaviour similar to the Raman spectrum of NaW-40 with only a slight shift of the frequency position assigned to the intrinsic atomic properties of the $\mathrm{Li}^{+}$and $\mathrm{Na}^{+}$ions. The intensity and the position of the Raman bands for the LiW-40 and NaW-40 glasses are clearly different compared to that seen for Li-40 [23]. Such differences suggest that $\mathrm{WO}_{3}$ has induced deep structural changes in the glass.

Firstly, it will be considered the general features of the $\mathrm{WO}_{3}$ niobiophosphate network and secondly, the modification of the niobiophosphate network of the $\mathrm{WO}_{3}$ free glass by tungsten oxide. In a $\mathrm{Li}-40$ glass-ceramic, peaks at $1300 \mathrm{~cm}^{-1}\left(v_{\mathrm{as}} \mathrm{P}=\mathrm{O}\right), 1100 \mathrm{~cm}^{-1}\left(v_{\mathrm{s}}\left(\mathrm{PO}_{2}\right)^{-}\right), 1050 \mathrm{~cm}^{-1}$ $\left(v_{\mathrm{s}}\left(\mathrm{PO}_{3}{ }^{2-}\right), 950 \mathrm{~cm}^{-1}\left(v_{\mathrm{s}}\left(\mathrm{PO}_{4}{ }^{3-}\right), 905 \mathrm{~cm}^{-1}\left(v_{\mathrm{s}}(\mathrm{Nb}-\mathrm{O})\right)\right.\right.$, $735 \mathrm{~cm}^{-1}\left(v_{\mathrm{s}}(\mathrm{P}-\mathrm{O}-\mathrm{P})\right), \quad 657$ and $605 \mathrm{~cm}^{-1}\left(v\left(\mathrm{NbO}_{6}\right)\right)$, $420-225 \mathrm{~cm}^{-1}\left(v\left(\mathrm{NbO}_{6}\right)\right.$, and $186 \mathrm{~cm}^{-1}\left(\delta\left(\mathrm{PO}_{4}\right)\right)$, are observed. The changes of the intensity and/or the position of these bands from a free- $\mathrm{WO}_{3}$ to $\mathrm{AW}-40$ glasses could help to get more insight into the effect of $\mathrm{WO}_{3}$ on the niobiophosphate network. On the basis of the assignments of Raman spectra for the $\mathrm{Li}_{2} \mathrm{O}-\mathrm{P}_{2} \mathrm{O}_{5}$ glass [28], the bands at around $600-760 \mathrm{~cm}^{-1}$ are due to P-O-P (bridging oxygen) stretching modes. The Raman bands in the region from 900 to $1300 \mathrm{~cm}^{-1}$ are associated with stretching vibrations of $\mathrm{Q}^{3}, \mathrm{Q}^{2}, \mathrm{Q}^{1}$, and $\mathrm{Q}^{0}$ species. The low-frequency region bands are due to bending modes. By analogy, the following attributions can be made [28]: the bands at $1141 \mathrm{~cm}^{-1}$ can be associated to symmetrical vibrations $v_{\mathrm{s}}\left(\mathrm{PO}_{2}\right)^{-}$; the band in the range $1228-1275 \mathrm{~cm}^{-1}$ can be assigned to the vibrations of antisymmetric elongation $v_{\mathrm{as}}(\mathrm{P}=\mathrm{O})$; the broadband observed in $1040-1070 \mathrm{~cm}^{-1}$ probably corresponds to the vibration of symmetrical elongation $v_{\mathrm{s}}\left(\mathrm{PO}_{3}{ }^{2-}\right)$; the band near $763-766 \mathrm{~cm}^{-1}$ is ascribed to $v_{\mathrm{s}}(\mathrm{P}-\mathrm{O}-\mathrm{P})$ vibration in the phosphate chains. The broadband in the range 590-640 $\mathrm{cm}^{-1}$ contains three components: the more intense band centered at $618 \mathrm{~cm}^{-1}$ must be ascribed to the vibrations of elongation $v_{\mathrm{s}}(\mathrm{POM})(\mathrm{M}=\mathrm{Nb}, \mathrm{W})$; the shoulder observed around $590 \mathrm{~cm}^{-1}$ results, probably, from the same modes of vibration, whereas the shoulder observed around $640 \mathrm{~cm}^{-1}$ can arise from the elongation of $\mathrm{M}-\mathrm{O}-\mathrm{M}$ groups $(\mathrm{M}=\mathrm{Nb}$, $\mathrm{W})$. The band around $511-566 \mathrm{~cm}^{-1}$ is probably connected to the vibrations of phosphate units deformation. Lastly, the three components at $184 / 154 ; 271 / 253 ; 373 / 382 \mathrm{~cm}^{-1}$ of the bands located in the frequency range $100-400 \mathrm{~cm}^{-1}$ are associated with the deformation modes of $\left(\mathrm{MO}_{6}\right)$ units.

The addition of $\mathrm{WO}_{3}$ promotes an increase in the number of $\mathrm{W}-\mathrm{O}$ bonds, which present a higher polarizability when compared with the $\mathrm{P}-\mathrm{O}$ bonds, masking the spectrum associated with the entities of phosphate structural units. These latter are in shoulder of the very intense bands associated with the vibrations of $\mathrm{W}-\mathrm{O}$ and/or $\mathrm{Nb}-\mathrm{O}$. Due to the fact that the $\mathrm{Nb}-\mathrm{O}$ and $\mathrm{W}-\mathrm{O}$ bonds possess both similar atomic properties and high polarisability, the bands characteristic of the vibrations of $\mathrm{Nb}-\mathrm{O}$ and $\mathrm{W}-\mathrm{O}$ overlap and appear in the same frequency positions of the spectra.

In the high-frequency region, the substitution of $\mathrm{Li}_{2} \mathrm{O}$ by $\mathrm{WO}_{3}$, when we move from $40 \mathrm{P}_{2} \mathrm{O}_{5}-10 \mathrm{Nb}_{2} \mathrm{O}_{5}-50 \mathrm{Li}_{2} \mathrm{O}$ $\left(\mathrm{WO}_{3}\right.$-free) to $40 \mathrm{P}_{2} \mathrm{O}_{5}-10 \mathrm{Nb}_{2} \mathrm{O}_{5}-20 \mathrm{WO}_{3}-30 \mathrm{Li}_{2} \mathrm{O}(\mathrm{LiW}-40)$, 
TABLE 2: Raman band positions of the LiW-40 and NaW-40 samples and their assignments.

\begin{tabular}{|c|c|c|c|c|}
\hline \multicolumn{2}{|c|}{ LiW-40 } & \multicolumn{2}{|c|}{$\mathrm{NaW}-40$} & \multirow{2}{*}{ Assignment } \\
\hline Band position & Width $\left(\mathrm{cm}^{-1}\right)$ & Band position & Width $\left(\mathrm{cm}^{-1}\right)$ & \\
\hline 160.98 & 64.94 & 159.53 & 63.30 & Deformation \\
\hline 250.81 & 133.03 & 253.69 & 132.79 & Deformation \\
\hline 377.69 & 112.73 & 382.93 & 80.54 & Deformation \\
\hline 566.96 & 33.02 & 544.04 & 24.03 & Deformation \\
\hline 591.63 & 22.08 & 578.07 & 71.09 & $v(\mathrm{Nb}-\mathrm{O})$ \\
\hline 614.67 & 29.68 & 616.77 & 40.38 & $v(\mathrm{Nb}-\mathrm{O})$ \\
\hline 640.67 & 25.74 & 639.76 & 23.78 & $\delta(\mathrm{Nb}-\mathrm{O})-\delta(\mathrm{POP})$ \\
\hline 764.52 & 90.62 & 763.39 & 86.42 & $v(\mathrm{M}-\mathrm{O}-\mathrm{P})$ \\
\hline 834.19 & 72.51 & 843.44 & 82.50 & $v(\mathrm{~W}-\mathrm{O})$ \\
\hline 893.16 & 66.56 & 916.07 & 54.02 & $v(\mathrm{Nb}-\mathrm{O}) / v(\mathrm{~W}-\mathrm{O})$ \\
\hline \multirow[t]{2}{*}{956.63} & 66.56 & 958.59 & 40.08 & $v(\mathrm{~W}-\mathrm{O})$ \\
\hline & & 979.50 & 84.02 & $v(\mathrm{Nb}-\mathrm{O})$ and/or $v(\mathrm{~W}-\mathrm{O})$ \\
\hline 1017.92 & 74.18 & & & $v(\mathrm{Nb}-\mathrm{O})$ \\
\hline 1075.26 & 72.50 & 1038.15 & 106.63 & $v_{s}\left(\mathrm{PO}_{3}\right)^{2-}$ \\
\hline 1144.61 & 87.79 & 1129.17 & 136.90 & $v_{s}\left(\mathrm{PO}_{2}\right)^{-}$ \\
\hline 1234.05 & 88.50 & 1249.22 & 78.98 & $v_{\mathrm{as}}\left(\mathrm{PO}_{2}\right)^{-}$and/or $v(\mathrm{PO})$ \\
\hline
\end{tabular}

can be related with the shift to low frequencies of the band centered at $1300 \mathrm{~cm}^{-1}$ to $1228-1275 \mathrm{~cm}^{-1}$; a shift of $1100 \mathrm{~cm}^{-1}$ to $1125-1141 \mathrm{~cm}^{-1}$, the appearance of a band at $980-1017 \mathrm{~cm}^{-1}$; the increase of the intensity of the bands near $950-960 \mathrm{~cm}^{-1}$; the appearance of bands near $916 \mathrm{~cm}^{-1}$, $840 \mathrm{~cm}^{-1}$ and $766 \mathrm{~cm}^{-1}$. These evolutions can be ascribed to the incorporation of niobium and/or tungsten ions into the phosphate network and formation of mixed structural units of the type P-O-M, M-O-M ( $\mathrm{M}=\mathrm{Nb}, \mathrm{W})$ linkages. The appearance of bands near $980,916,900$, and $1017 \mathrm{~cm}^{-1}$ indicates the presence of $\left(\mathrm{NbO}_{6}\right)$ units with different distortion in the glass matrix. The bands around $980 \mathrm{~cm}^{-1}$ and $1017 \mathrm{~cm}^{-1}$ are seen in the Raman spectrum of $\mathrm{NbOPO}_{4}$ crystalline phase, so the band at $979.5 \mathrm{~cm}^{-1}$ and $1017 \mathrm{~cm}^{-1}$ for NaW-40 and LiW-40, respectively, do indicate the presence of motifs $\mathrm{PO}_{4}$ and $\mathrm{NbO}_{6}$, in the structure of $\mathrm{AW}-40$ glasses, linked in the same way as in the crystalline $\mathrm{NbOPO}_{4}$. This result is in agreement with the X-ray analysis of the crystallised NaW40 and LiW-40 samples. It is worth to note that the band at $979.5 \mathrm{~cm}^{-1}$ could be correlated to the monoclinic symmetry since the identification of such structural arrangement is made by X-ray diffraction for NaW-40 sample (Figure 2).

The crystalline $\alpha-\mathrm{NbOPO}_{4}$ contains octahedral chains $\left[\mathrm{NbO}_{6}\right]$ parallel with the $c$-axis. These chains are connected between them by tetrahedrons $\left[\mathrm{PO}_{4}\right]$ to form a threedimensional structure; these corner sharing polyhedrons $\left[\mathrm{NbO}_{6}\right]$ do not have terminal oxygen ions but they are distorted, giving an alternation of short and long bonds [31]. This structure shows a Raman band at $800 \mathrm{~cm}^{-1}$. On the other hand, one can note that the frequency positions of $\mathrm{NbO}_{6}$ modes in LiW-40 and NaW-40 are higher than in $\alpha-\mathrm{NbOPO}_{4}$, suggesting that the symmetry and/or the degree of connectivity of the $\mathrm{NbO}_{6}$ in the glasses are different from the existing in the $\alpha-\mathrm{NbOPO}_{4}$ phase. Shannon [32] clearly highlighted the displacement of the bands towards higher frequencies when the degree of distortion of octahedral increases but also when the number of terminal bonds $\mathrm{Nb}-\mathrm{O}_{T}$ pointing towards modifying ions grows. Therefore, the bands observed around $950-980 \mathrm{~cm}^{-1}, 900-917 \mathrm{~cm}^{-1}$ can be ascribed to the distorted $\left[\mathrm{NbO}_{6}\right]$ octahedral having at least a short $\mathrm{Nb}-\mathrm{O}$ bond pointing towards a modifying ion. The band around $840 \mathrm{~cm}^{-1}$ could be associated to the $\mathrm{Nb}-\mathrm{O}$ vibrations in distorted octahedral which can present an association by their corners with at least another octahedra of niobium. The emergence of broadband near $760-770 \mathrm{~cm}^{-1}$ can be explained by the presence in the glass matrix of the $\mathrm{Nb}-\mathrm{O}$ vibration in less distorted $\mathrm{NbO}_{6}$ octahedral. The increase in the relative intensity of this last band in LiW-40 glass compared to that of NaW-40 glass, which can certainly be interpreted like an increase in more symmetrical octahedral $\left[\mathrm{NbO}_{6}\right]$ sites, is in agreement with the identification by $\mathrm{X}$ ray diffraction of high-symmetry orthorhombic $\mathrm{NbOPO}_{4}$ phase in LiW-40 sample and a monoclinic phase in NaW40 one. Generally, the presence of bands below $790 \mathrm{~cm}^{-1}$ suggests the existence of less distorted octahedral units [33]. The bands around $640,616,590-580$, and $566-511 \mathrm{~cm}^{-1}$ can be associated with the $\mathrm{Nb}-\mathrm{O}$ modes of less distorted octahedral. More precisely, by comparison with the spectra obtained for borophosphate of sodium and niobium, the band around $638 \mathrm{~cm}^{-1}$ can be the reflection of a beginning of association of octahedra to form a three-dimensional network [34]. Lastly, the area of $380-100 \mathrm{~cm}^{-1}$ corresponds to the movements of angular $\mathrm{O}-\mathrm{Nb}-\mathrm{O}$ deformation. The bands around $382-372 \mathrm{~cm}^{-1}$ and $271-256 \mathrm{~cm}^{-1}$ can thus be connected to the vibrations relating to the octahedral distortion.

It is worth to note that the nonidentification, by X-ray diffraction, of pyrophosphate and orthophosphate precipitate 
phases (Figure 2) indicates that phosphate network is more polymerised in AW-40 glasses in agreement with the Raman spectra (Figures 3 and 4), which show high-frequency bands near $1280 \mathrm{~cm}^{-1}$.

The appearance of the latter band can be explained if we consider that a part of the network modifier species $\mathrm{A}_{2} \mathrm{O}$ is transferred from the phosphate to the niobium $\mathrm{NbO}_{6}$ unit since the charge balance requires that the average degree of polymerization for the phosphate species must increase. We can formulate this oxygen redistribution in terms of a chemical equilibrium, involving the reaction of anionic phosphate units with $\mathrm{NbO}_{6 / 2}{ }^{-}$octahedra to form $\mathrm{Q}^{2}$ units and anionic niobium species:

$$
\begin{aligned}
& \left(\mathrm{Q}^{0}\right) \mathrm{O}=\mathrm{PO}_{3}{ }^{3-}+\mathrm{NbO}_{6 / 2}{ }^{-} \\
& \longrightarrow \mathrm{O}=\mathrm{PO}_{1 / 2} \mathrm{O}_{2}{ }^{2-}+\mathrm{NbO}_{5 / 2} \mathrm{O}^{2-} \\
& \left(\mathrm{Q}^{1}\right) \mathrm{O}=\mathrm{PO}_{1 / 2} \mathrm{O}_{2}{ }^{2-}+\mathrm{NbO}_{6 / 2}{ }^{-} \\
& \longrightarrow \mathrm{O}=\mathrm{PO}_{2 / 2} \mathrm{O}^{-}+\mathrm{NbO}_{5 / 2} \mathrm{O}^{2-}
\end{aligned}
$$

Also, the presence of nonbridging oxygen ions on the niobium units is in agreement with the presence of several components in the Raman bands located between 800 and $950 \mathrm{~cm}^{-1}$.

\section{Conclusion}

Glasses of the system $\mathrm{A}_{2} \mathrm{O}-\mathrm{WO}_{3}-\mathrm{Nb}_{2} \mathrm{O}_{5}-\mathrm{P}_{2} \mathrm{O}_{5}(\mathrm{~A}=\mathrm{Li}, \mathrm{Na})$ were prepared by the melt quenching and their structure was studied by thermal analysis, X-ray diffraction, SEM microscopy, and Raman spectroscopy. It was found that the introduction of tungsten into these alkali niobiophosphate glasses induces the creation of additional nonbridging oxygen ions and/or the formation of larger niobium- and/or tungsten-containing structural units such as $\mathrm{WO}_{6} / \mathrm{NbO}_{6}$ octahedra in the glass network.

The thermal analysis showed that the $\mathrm{AW}-40$ glasses are more stable than the $\mathrm{WO}_{3}$-free glass and that the NaW-40 presents the lowest thermal stability and the highest tendency towards crystallization, when compared with the LiW-40 glass.

In the lithium-niobiophosphate glasses, the $\mathrm{XRD}$ results indicate that the replacement of $\mathrm{Li}_{2} \mathrm{O}$ by $\mathrm{WO}_{3}$ reduces the number of the crystallised phases. The presence of $\mathrm{WO}_{3}$ in those glasses promotes the formation of $\mathrm{NbOPO}_{4}$ instead of the $\mathrm{LiNbO}_{3}$ phase and favours the network polymerisation due to the nonformation of pyrophosphate and orthophosphate phases. The decreasing of amorphous character, with the increase of the heat treatment temperature, is associated with the substitution of ionic alkali-oxygen bonds by covalent $\mathrm{W}-\mathrm{O}$. In all AW-40 glasses, the network structure is dominated by orthophosphate $\mathrm{Q}^{0}$ groups. The Raman spectra of those glasses indicate that the arrangements of the network structural units are less affected by the heat treatments conditions.

\section{Acknowledgment}

The authors are grateful to the CNRST (Morocco)-FCT (Portugal) for the financial support offered to this work.

\section{References}

[1] B. C. Sales and L. A. Boatner, "Physical and chemical characteristics of lead-iron phosphate nuclear waste glasses," Journal of Non-Crystalline Solids, vol. 79, no. 1-2, pp. 83-116, 1986.

[2] Y. B. Peng and D. E. Day, "High thermal expansion phosphate glasses. Part 1," Glass Technology, vol. 32, no. 5, pp. 166-173, 1991.

[3] N. Aranha, O. L. Alves, L. C. Barbosa, and C. L. Cesar, "The role of $\mathrm{Nb}_{2} \mathrm{O}_{5}$ on the chemical durability of $\mathrm{P}_{2} \mathrm{O}_{5}-\mathrm{Nb}_{2} \mathrm{O}_{5}-\mathrm{PbO}-\mathrm{K}_{2} \mathrm{O}$ glass system," in Proceedings of the 17thInternational Congress Glass, vol. 7, p. 282, Beijing, China, 1995.

[4] G. Fuxi, "New glass-forming systems and their practical application," Journal of Non-Crystalline Solids, vol. 123, no. 1-3, pp. 385-399, 1990.

[5] L. D. Bogomolova, "The effects of copper impurity in vanadate and tungsten-phosphate glasses," Journal of Non-Crystalline Solids, vol. 30, no. 3, pp. 379-383, 1979.

[6] S. Krimi, A. El Jazouli, L. Rabardel, M. Couzi, I. Mansouri, and G. Le Flem, "Glass Formation in the $\mathrm{Na}_{2} \mathrm{O}-\mathrm{TiO}_{2}-\mathrm{P}_{2} \mathrm{O}_{5}$ System," Journal of Solid State Chemistry, vol. 102, no. 2, pp. 400-407, 1993.

[7] E. M. Vogel, "Glasses as nonlinear photonic materials," Journal of the American Ceramic Society, vol. 72, no. 5, pp. 719-724, 1989.

[8] L. A. Farrow and E. M. Vogel, "Raman spectra of phosphate and silicate glasses doped with the cations $\mathrm{Ti}, \mathrm{Nb}$ and $\mathrm{Bi}$," Journal of Non-Crystalline Solids, vol. 143, no. C, pp. 59-64, 1992.

[9] N. V. Nikonorov and G. T. Petrovskii, "Ion-exchanged glasses in integrated optics: The current state of research and prospects (a review)," Glass Physics and Chemistry, vol. 25, no. 1, pp. 16-55, 1999.

[10] R. K. Brow and D. R. Tallant, "Structural design of sealing glasses," Journal of Non-Crystalline Solids, vol. 222, pp. 396-406, 1997.

[11] D. K. Sardar, J. B. Gruber, B. Zandi, J. A. Hutchinson, and C. Ward Trussell, "Judd-Ofelt analysis of the $\mathrm{Er}^{3+}\left(4 f^{11}\right)$ absorption intensities in phosphate glass: $\mathrm{Er}^{3+}, \mathrm{Yb}^{3+}$, , Journal of Applied Physics, vol. 93, no. 4, pp. 2041-2046, 2003.

[12] K. Franks, V. Salih, J. C. Knowles, and I. Olsen, "The effect of $\mathrm{MgO}$ on the solubility behavior and cell proliferation in a quaternary soluble phosphate based glass system," Journal of Materials Science: Materials in Medicine, vol. 13, p. 549, 2002.

[13] B. C. Sales and L. A. Boatner, "Lead-iron phosphate glass," in Radioactive Waste Forms for the Future, W. Lutze and R. C. Ewing, Eds., p. 193, North-Holland, 1988.

[14] A. H. Khafagy, S. M. ElpRabaie, A. A. Higazy, and A. S. Eid, "Absorption spectra of zinc-phosphate glasses doped with $\mathrm{Nd}_{2} \mathrm{O}_{3}$ rare earth oxide," Indian Journal of Physics A, vol. 74, p. $433,2000$.

[15] B. C. Sales and L. A. Boatner, "Optical, structural, and chemical characteristics of lead-indium phosphate and lead-scandium phosphate glasses," Journal of the American Ceramic Society, vol. 70, no. 9, pp. 615-621, 1987.

[16] W. S. Key and J. C. Miller, "Phosphate glass for photonics," ORNL Review, vol. 27, no. 3, p. 12, 1994. 
[17] I. W. Donald, "Preparation, properties and chemistry of glassand glass-ceramic-to-metal seals and coatings," Journal of Materials Science, vol. 28, no. 11, pp. 2841-2886, 1993.

[18] S. F. Anvari, C. A. Hogarth, and G. R. Moridi, "Electrical conductivity of zinc-barium phosphate glasses," Journal of Materials Science, vol. 26, no. 13, pp. 3639-3642, 1991.

[19] R. Pyare, L. J. Lal, V. C. Joshi, and V. K. Singh, "Leachability of molybdenum from ternary phosphate glasses," Journal of the American Ceramic Society, vol. 79, no. 5, pp. 1329-1334, 1996.

[20] G. E. Rachkovskaya and N. M. Bobkova, "Semiconducting niobate-phosphate glasses. Structure and properties," Journal of Non-Crystalline Solids, vol. 90, no. 1-3, pp. 617-620, 1987.

[21] E. B. De Araujo, J. A. C. De Paiva, M. A. B. De Araujo, and A. S. B. Sombra, "Structure and optical properties of lithium niobium-phosphate glasses and glass ceramics," Physica Status Solidi B, vol. 197, no. 1, pp. 231-240, 1996.

[22] M. P. F. Graça, M. G. Ferreira da Silva, A. S. B. Sombra, and M. A. Valente, "Electrical and dielectrical properties of $\mathrm{SiO}_{2}-\mathrm{Li}_{2} \mathrm{O}-$ $\mathrm{Nb}_{2} \mathrm{O}_{5}$ glass and glass-ceramics obtained by thermoelectric treatments," Journal of Non-Crystalline Solids, vol. 352, no. 42-49, pp. 5199-5204, 2006.

[23] M. P. F. Graça, M. A. Valente, and M. G. Ferreira da Silva, "The electric behavior of a lithium-niobate-phosphate glass and glass-ceramics," Journal of Materials Science, vol. 41, 2006.

[24] T. G. Amos and A. W. Sleight, "Negative thermal expansion in orthorhombic $\mathrm{NbOPO}_{4}$," Journal of Solid State Chemistry, vol. 160, no. 1, pp. 230-238, 2001.

[25] A. LeClaire, H. Chahboun, D. Groult, and B. Raveau, "The crystal structure of $\beta$-NbPO 5 ," Zeitschrift für Kristallographie, vol. 177, no. 3, pp. 277-286, 1986.

[26] T. G. Amos, A. Yokochi, and A. W. Sleight, "Phase transition and negative thermal expansion in tetragonal $\mathrm{NbOPO}_{4}$," Journal of Solid State Chemistry, vol. 141, no. 1, pp. 303-307, 1998.

[27] L. Bih, L. Abbas, S. Mohdachi, and A. Nadiri, "Thermal and electrical properties of mixed alkali in $\mathrm{Li}_{2} \mathrm{O}-\mathrm{Na}_{2} \mathrm{O}-\mathrm{WO}_{3}-\mathrm{P}_{2} \mathrm{O}_{5}$ glasses," Journal of Molecular Structure, vol. 891, no. 1-3, pp. 173-177, 2008.

[28] R. K. Brow, "Review: the structure of simple phosphate glasses," Journal of Non-Crystalline Solids, vol. 263-264, pp. 1-28, 2000.

[29] U. Hoppe, "A structural model for phosphate glasses," Journal of Non-Crystalline Solids, vol. 195, no. 1-2, pp. 138-147, 1996.

[30] W. Vogel and W. Höland, "The development of bioglass ceramics for medical applications," Angewandte Chemie, vol. 26, pp. 527-544, 1987.

[31] A. A. Mc. Connel, J. S. Anderson, and G. N. R. Rao, "Raman spectra of niobium oxides," Spectrochimica Acta Part A, vol. 32, no. 5, pp. 1067-1076, 1976.

[32] R. D. Shannon, "Revised effective ionic radii and systematic studies of interatomic distances in halides and chalcogenides ," Acta Crystallographica A, vol. 32, pp. 751-767, 1976.

[33] K. Fukumi and S. Sakka, "Coordination state of $\mathrm{Nb}^{5+}$ ions in silicate and gallate glasses as studied by Raman spectroscopy," Journal of Materials Science, vol. 23, p. 2819, 1988.

[34] T. Cardinal, E. Fargin, G. Le Flem et al., "Non linear optical properties of some niobium (V) oxide glasses," European Journal of Solid State and Inorganic Chemistry, vol. 33, no. 7, pp. 597-605, 1996. 

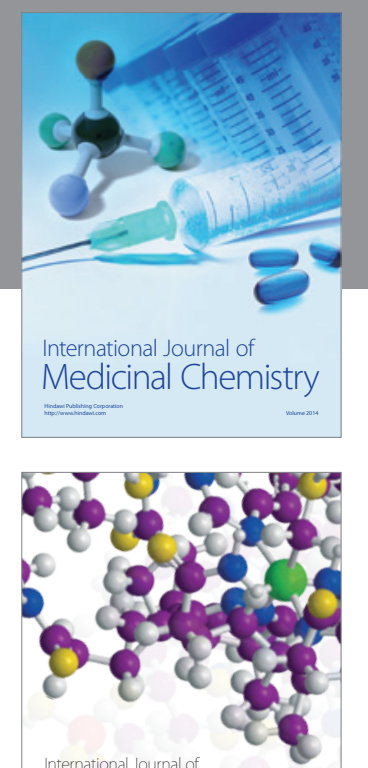

\section{Carbohydrate} Chemistry

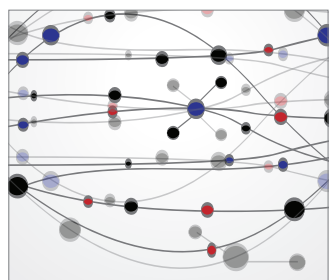

The Scientific World Journal
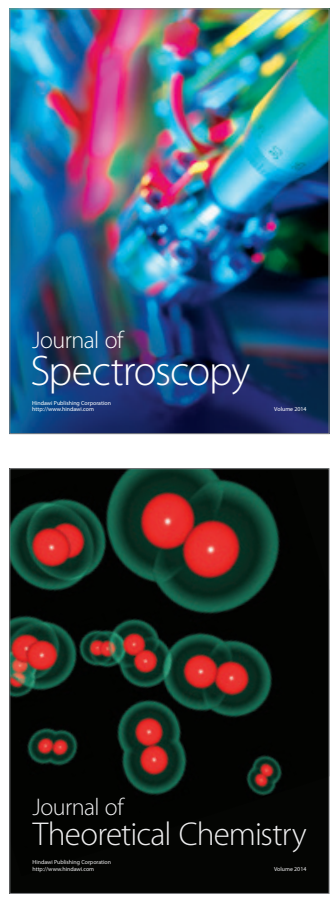
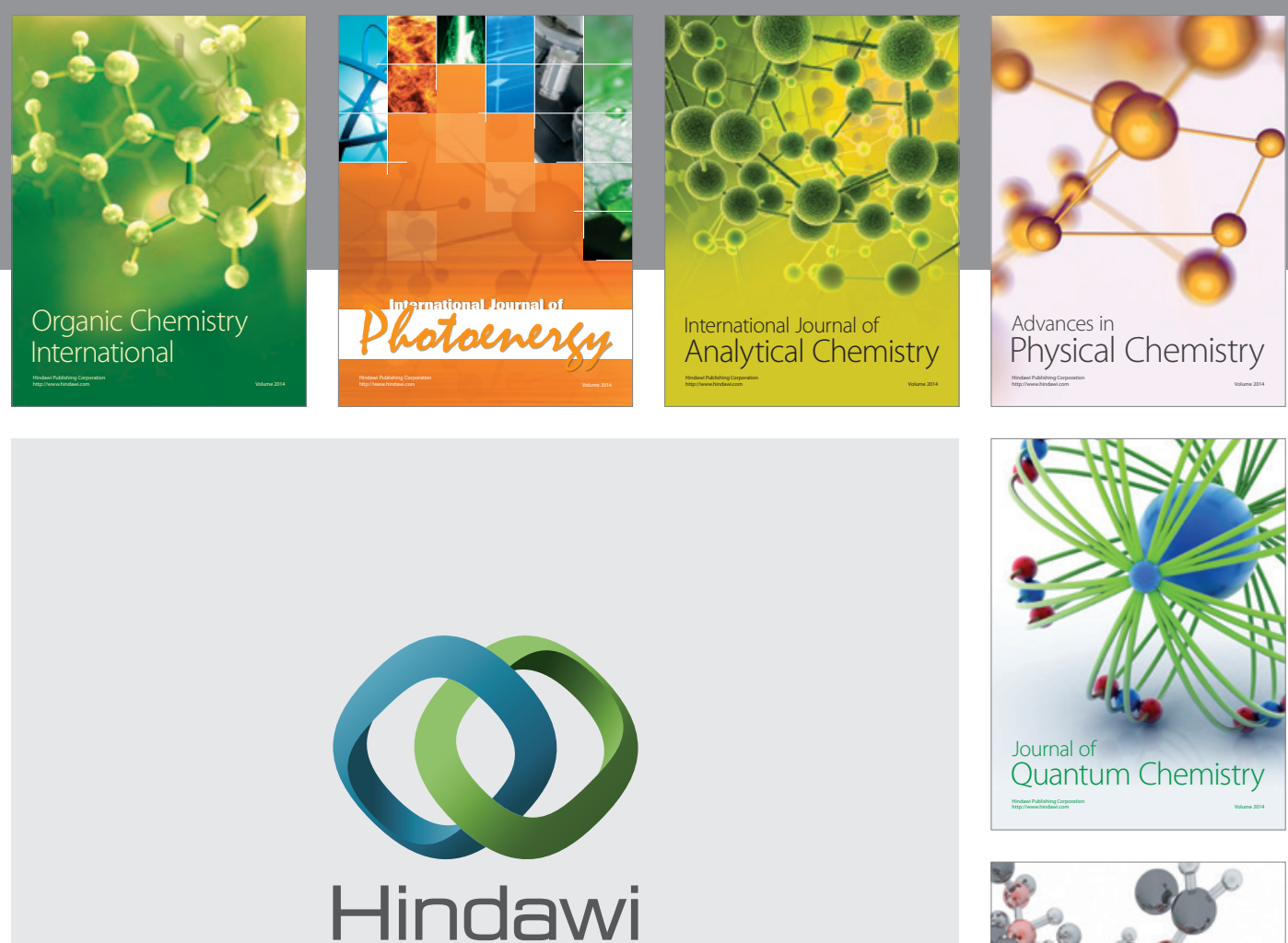

Submit your manuscripts at

http://www.hindawi.com

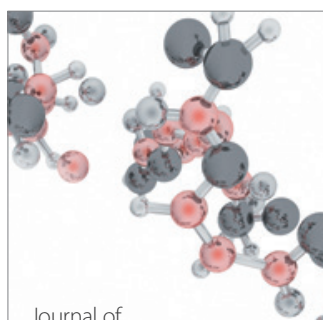

Analytical Methods

in Chemistry

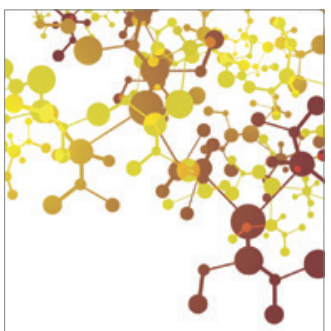

Journal of

Applied Chemistry

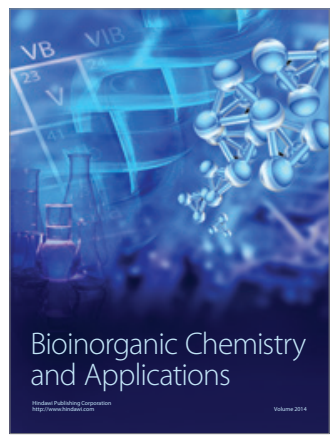

Inorganic Chemistry
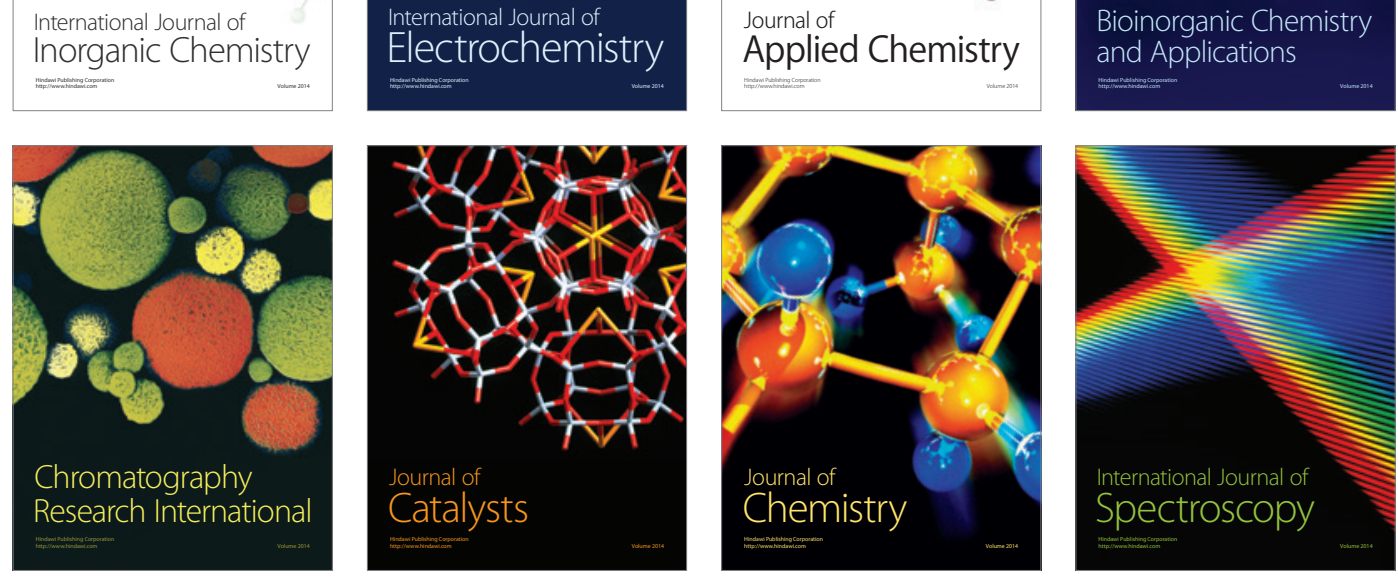